\title{
Specific Character of Formation of Competitive Development Strategies in the Information - Communication Services Market
}

\author{
Tatyana N. Petrova \\ Marina B. Kozhanova \\ Chuvash State Pedagogical University named after I.Y. Yakovlev, Cheboksary, Russia \\ Email: tanjana1@yandex.ru \\ Raisa I. Platonova \\ North-Eastern Federal University named after M.K. Ammosov, Yakutsk, Russia \\ Sergey V. Kiselev \\ Kazan National Research Technological University, Kazan, Russia \\ Mikhail G. Kharitonov \\ Irina G. Ershova
}

Chuvash State Pedagogical University named after I.Y. Yakovlev, Cheboksary, Russia

Ludmila V. Marfina

Kazan State University of Architecture and Engineering, Kazan, Russia

Doi:10.5901/mjss.2015.v6n2s3p113

\section{Abstract}

In the context of growing globalization processes and the entry of Russia into the international information space the problems of competitiveness of domestic operators in the information - communication services market are actualizing. On the basis of analysis and use of the "matrix of strategic actions of a service company" the main specific organizational and managerial features of construction and implementation of competitive development strategies for the information - communication services market participants are considered, the comparative characteristics of the development of competitive strategies in the market of information and communication services by traditional methods of strategic planning are considered, the benefits of "divisional" structures and their specificity in the market of information and communication services are justified. This article is intended for students studying methods of marketing research in the service industries, as well as marketing specialists, operators who develop strategies of their companies growth.

Keywords: competition, strategy, market, information and communication services, divisional structures.

\section{Introduction}

One of the global trends in a modern industrial and economic environment of society is the predominance of the service sector, the so-called tertiary sector of the economy over the industrial sectors: a primary one - the extractive industries and agriculture, a secondary one - manufacturing industries. The fifth industrial is the last cycle of industrial development and is a kind of transition to a post-industrial information - service society. The development of a modern economy is characterized by a rapid growth of the service sector compared with its other sectors (Schumpeter, 1982).

This manifests itself in the rapidly growing share of services in the gross domestic product of the leading countries of the world that has reached $70 \%$ in the United States, in other countries more than $60 \%$, in developing countries almost close to 50\%, and in Russia it is about 53\% (Andreeva \& Mirgorodskaya, 2004). The transformation of the service sector 
in the dominant sector of the national economy for the production of gross domestic product and employment coincided with the information technology revolution, when, at the end of the XX century, in order to replace the industrial society of the extensive type the information-service society of the intensive type of development comes. The accelerated development of the service sector is also associated with an increase in the social division of labor as a result of scientific and technical progress, and on this basis, raising the material well-being and improvement of their life quality (Danilin, 2004).

In the context of the transformation stage of the national economy development the setting up and maintenance of the competitiveness has become a major concern of all business organizations in the sphere of services regardless of their size. Structural and institutional changes in global and national economies are diversified and uneven, that essentially transforms the nature of the relationship between competing business entities. It is possible to comply with the taking place changes only on the basis of growth of competitiveness of enterprise structures (enterprises, companies, firms), industries, regions and states. However, it is important to understand that competitive or non-competitive positions of specific companies and industries are always responsible for the rating of the country (Gelvanovsky, 2003).

All this requires the formation of an adequate development strategy on one of the largest segments of the service market, which is the market of information -communication services, acting as a strategically important sector of the national economy, ensuring the development and strengthening of the state community of people, their livelihoods and implementation of the major social rights of civil society (Andreeva \& Mirgorodskaya, 2004).

The urgency of this problem increases significantly due to the increasing dependence of the main parameters of the socio-economic development of regions and the level of information - communication services market development (Courbiev \& Kiselev, 2010).

\section{Methodological Framework}

\subsection{The objectives of the research}

The objectives of the study is to develop the theoretical foundations and practical recommendations for the establishment and effective functioning of a competitive strategy in the regional market of information - communication services, interaction of this market subjects, as well as methods of state regulation of the process of its development, including the study of specific features of the competitive environment formation in the regional market of information-communication services, the specific characteristics of the institutional forms of territorial associations of the subjects of the information communication services regional market.

\subsection{Theoretical and methodological framework}

Theoretical and methodological basis of research are the works of domestic and foreign scholars in the field of regional markets theory, as well as the specific features of the individual local markets functioning.

In the process of research there are used dialectical and system analysis methods, methods of abstraction and comparison, statistical surveys, economic and mathematical methods in the calculation of averages, groupings of economic indicators, modeling methods and expert evaluation.

\section{Results}

There are distinguished specific features of the institutional forms of a regional service market unification that are aimed at the use of quality factors of a corporate strategy and the level of information - communication technologies development, a high degree of diversification of information - communication services, orientation on customers of the regional market certain segments.

The study of the largest telecom operators in the Volga Federal District revealed a set of interrelated organizational and management problems damping their further development. The most important problems are the outdated management and organizational structure, the absence of an analytical professional approach to studying the condition of information and communication service market segment, the lack of competitive strategy of development with certain defined objectives, priorities and deadlines for achieving them. All this is greatly urgent regarding the problems of formation of the competitive development strategies in the information - communication services market.

Organizational and managerial features of functioning of modern business forms in the field of information communication services are due to the specifics of certain activities that have an ambiguous effect on the processes of 
management of business structures. It is necessary to take into account the specific features of the information communication services market, which can be described as follows.

Firstly, this market segment is characterized by the massive introduction of modern high-tech means of information communications, mainly multiservice orientation, which entails a radical reconstruction of networks and the rapid drop in economic efficiency and competitiveness of traditional networks used to transmit information of only one type (Rokotyan, 2006; Kotilko \& Sanin, 2003).

Secondly, a sharp intensification of competition in the most dynamic segments of the market, such as mobile telephony, Internet and services for corporate users, has led to an increase of consumers' market power and their everincreasing pressure on prices of information - communication services operators. As the annual reports data of the leading domestic operators of information - communication services show that the profitability of basic services in the segments of fixed-line market has a steady downward trend that forces operators to look for new ways to preserve profitability (Efanov, 2006). This trend is proved by the stop of classic telephony market growth in developed countries against the high penetration of mobile networks and the rapid growth in the number of broadband connections.

Thirdly, a unified business model of providing information -communication services, including the creation of the operator's own network, its operation and providing services to consumers on its basis, under the influence of the abovementioned trend is divided into two independent infrastructural and service models. In this case, the most important component of a competitive strategy in the information - communication services market becomes a marketing component, considering the service not as a technological product of information and communication services network, but as an object of sale.

Fourthly, the most important feature of the market orientation of the modern process of information communication services sale is the deep diversification of market segments, the ability to get a variety of services in one place, using a single, so-called "operating window". This trend leads to the formation of specialized intermediary companies, which in foreign countries make up a whole category of virtual operators that do not have their own network infrastructure but having the ability to complete various combinations of services purchased at wholesale prices from the network operators and resell them in the form of packages to end-users under their own brand name. In this case, the virtual operator can add to a service package a significant amount of services organized by himself both information communication ones and services that have nothing in common with them.

There are formed comparative characteristics of the competitive development strategies in the information communication services market by means of traditional and strategic planning methods

Table 1. Comparative characteristics of the development of competitive strategies in the information - communication services market by means of traditional and strategic planning methods

\begin{tabular}{|c|c|c|}
\hline \multirow{2}{*}{ № } & \multicolumn{2}{|c|}{ The main characteristics of two types planning } \\
\hline & Traditional & Strategic \\
\hline 1 & Current, short-term, medium-term & Long-term, prospective \\
\hline 2 & Administrative and managerial approach & System problem-oriented approach \\
\hline 3 & It solves several current tasks & It solves the set of many interrelated current and future tasks \\
\hline 4 & Orientation on its own resources & $\begin{array}{l}\text { Orientation on their own and borrowed resources, as well as } \\
\text { partnership relationships }\end{array}$ \\
\hline 5 & Divisional structure & $\begin{array}{l}\text { Participation in flexible organizational forms of management, } \\
\text { including network structures }\end{array}$ \\
\hline 6 & $\begin{array}{l}\text { Hierarchical structure and management of } \\
\text { developments }\end{array}$ & Project, matrix and combined management of developments \\
\hline 7 & $\begin{array}{l}\text { Limited involvement of staff in the } \\
\text { developments }\end{array}$ & $\begin{array}{l}\text { The high level of involvement of different staff groups in new } \\
\text { developments }\end{array}$ \\
\hline 8 & $\begin{array}{l}\text { Performed for the top management of the } \\
\text { company }\end{array}$ & $\begin{array}{l}\text { Performed for all groups of stakeholders (staff, partners, investors, } \\
\text { creditors, customers) }\end{array}$ \\
\hline 9 & It does not require a high qualification & Requires the highest qualification level \\
\hline 10 & $\begin{array}{l}\text { Results are limited by a marked list of plans } \\
\text { and activities }\end{array}$ & The results are complex, multifaceted, dynamic, mutual \\
\hline
\end{tabular}

The process of strategy management formation and development of companies in the information - communication services market involves as an integral part and process of the strategic planning of the industry enterprises activities. In businesses and structures in the information - communication services market has rooted a traditional planning of 
activities (short- and medium-term) which virtually ignores the processes of influence the environment and market conditions, especially in the long-run period. Whereas modern conditions of functioning and development of highly integrated companies in the sector of information - communication services require a strategic approach, which has a number of advantages clearly presented in the table.

There has been adapted the matrix of competitive strategies of operators, depending on their economic situation and the potential capacity of the regional market of information - communication services. Substantial significance in determining competitive strategies of information - communication operators have their economic condition and the potential capacity of the market of information and communication services in the region. Using "the matrix of strategic actions of a service company" (Zaynasheva \& Shkabarnya, 2004), we attempted to impose its conditions on the algorithm of competitive strategies development of information and communication services operators, depending on the factors listed above (see Fig. 1).

\begin{tabular}{|c|c|c|c|c|}
\hline & \multicolumn{4}{|c|}{ Economic situation of a service company } \\
\hline & & Good & Medium & Satisfactory \\
\hline 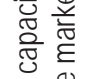 & Large & Expansion of innovation, investments & $\begin{array}{l}\text { Diversification, innovation, } \\
\text { cost reduction }\end{array}$ & $\begin{array}{l}\text { Getting into strategic } \\
\text { partnerships }\end{array}$ \\
\hline 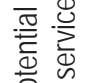 & Medium & $\begin{array}{l}\text { Diversification, innovation, } \\
\text { investments }\end{array}$ & $\begin{array}{l}\text { Getting into strategic } \\
\text { partnerships }\end{array}$ & Merger, restructuring \\
\hline 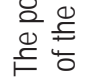 & Small & $\begin{array}{l}\text { The search for new markets, } \\
\text { diversification, innovation }\end{array}$ & $\begin{array}{l}\text { Merger, getting into strategic } \\
\text { partnerships }\end{array}$ & $\begin{array}{l}\text { Restructuring, transformation } \\
\text { bankruptcy }\end{array}$ \\
\hline
\end{tabular}

Figure 1. The matrix of competitive strategies of operators depending on their economic situation and the potential capacity of the information and communication services regional market

Strategic decisions, generated by this matrix, can be used to develop competitive strategies for further development of market participants of information - communication services in the region as a whole. A significant role in determining the potential capacity of the regional market of information - communication services belongs to the aggregation strategy, which is based on the most significant for the company socio-economic factors and features, it allows to consider this market segment as a homogeneous environment and, accordingly, to develop a system of organizational - economic and marketing activities. In most cases, the policy of aggregation leads to attempts of companies to influence the process of creating a demand for a particular segment of the information - communication services market. In other words, large companies often dictate their interests by their policies to the consumers.

The major component of aggregate resources and factors of the internal environment of modern information communication operator is the level of management, which essentially forms its potential competitiveness. The management of information - communication operators can be considered as a qualitative resource and an essential factor of their competitiveness. If the composition, structure, quantitative and qualitative characteristics of its own and attracted resources of the operator can be adequately estimated by using absolute figures, so the criteria of management development level are only relative indicators of use of all resources types - the levels of profitability, return on assets, solvency, financial stability, share market at this segment, the degree of needs satisfaction in information communication services. The positive dynamics of these indicators shows an increase in the competitiveness of information - communication operators in this segment of the regional market.

A characteristic feature of the modern development of highly integrated operators in the market of information communication services is that the classical linear-functional management structures are peculiar only to some small and medium-sized enterprises. This type of management structure construction is rarely used by large and major corporations and associations prevailing in the area of information - communication services. Most of all it is peculiar to their territorial divisions and branches. For large organizations in the information - communication services market divisional approach to building organizational management structures has become dominant. The appearance and development of divisional structures is due to the sharp increase in the size of companies and the scope of their activities, complicating of technological processes and economic links, diversification of the types of work and services. It is obvious that in a changing external environment it is becoming more difficult to manage from a single center rather diverse and geographically dispersed business units. Moreover the part of the administrative functions of information - communication services and in a number of other service industries associated with a direct customer service, clearly gravitating towards decentralization.

The analysis shows that the two types of divisional structures are widely used in the sphere of service in huge 
integrated companies: product and territorial (Zaynasheva \& Shkabarnya., 2004; Kotilko, 2003). The product divisional structure of a large company in the field of information - communication services can be characterized by the presence of a number of divisions that specialize in certain types (groups) of information - communication services, or multidisciplinary activities and being divisions with all their inherent autonomy and responsibility. These divisions are composed of services and structures providing the production, implementation of services and a direct customer service. Of course, the composition and structure of these internal services and departments may vary, it depends on the specific types of services and forms of customer service. This type of organizational and management structure is currently used in large and medium-sized multi-service companies, such as, for example, operators and service providers in the market of information - communication services providing a wide range of services to the population, as well as a variety of business services to legal entities. Service companies, which have such a management and organizational structure, are highly competitive and able to respond adequately quickly to changes in the conditions of competition in its market segment, to customer demand fluctuations and to changing priorities in customer service.

Along with a product divisional structure the varieties of territorial divisional structure got a wide spreading in the service sector in recent years. In this considered option, a service activity in a certain area (city, district) is assumed to be controlled through appropriate territorial offices (branches) bearing the full financial, production and economic responsibility for the results of their activities.

A territorial option of the divisional structure greatly facilitates the process of a company management as it can take into account regional conditions and characteristics of geographical, natural and climatic, national and legal features, traditions, customs and daily life of local people in full scale. This management structure is particularly effective in terms of remoteness and scattered settlements; it requires a maximum approaching of services to their customers. The management in the majority of the largest operators of telecommunications, insurance companies, financial and investment funds, network companies of after-sales service of sophisticated domestic and computer equipment and others is organized by territorial divisional structure.

The main advantages of divisional structures in the information - communication services market include the following:

- the use of divisional management structures enables the company to pay as much attention to specific types of services and consumers as a small specialized company can afford it, in the result that allows to respond much more effectively to the changes taking place in this market segment and adapt to them;

- the maximum orientation of the management structure on achievement the final results of company activities consisting in production and delivery of certain services, meeting the needs of certain customers, diversification of services in this market segment;

- the complexity reduction of quantitative and qualitative parameters of the senior management problems;

- the separation of operational and strategic levels of management that allows senior management of a company to focus on strategic planning and development;

- the transfer of responsibility for the final results on the level of divisions; that allows the management to adapt most effectively to the market situation in this market segment;

- improving and raising of efficiency of management divisional structures and their heads' initiative.

\section{Discussion}

The problems of formation and development of local markets in the framework of the theory and practice of regional economy are adequately represented in the works of foreign and domestic scientists.

Theoretical questions and the concept of regional markets, methods of economic evaluation of regional markets, a creation of a competitive environment and a market infrastructure are considered in the works of leading foreign scientists Y. Schumpeter (1982), F. Kotler (1992) and others.

Problems of formation of competitive strategy in the services sector are considered in the works of L. Andreeva \& E. Mirgorodskaya (2004), G.L. Azoev \& A.P. Chelenkov (2000), M.I. Gelvanovsky (2003), E.N. Zhiltsov \& V.N. Kazakov (2007), Z.G. Zaynasheva \& G.V. Shkabarnya (2004), I.U. Courbiev \& S.V. Kiselev (2010), Kulibanova V.V. (2002), Lifits R.A. (2001) and others.

The foundation of modern research in the field of information and communication services market development and its role in regional development was laid in the works of L.E. Varakin (2006), A.V. Danilin (2004), A.V. Efanov (2006), I.U. Courbiev \& S.V. Kiselev (2010), V.V. Kotilko \& I.I. Sanin (2003), S.B. Perminov (2007), A.U. Rokotyan (2006) and others.

However, despite a large number of works of Russian and foreign authors, there remains a big list of issues related 
to the development of regional strategies for information - communication services market development and their impact on the socio-economic development of regions.

\section{Conclusion}

Formation of associations of various types on the information - communication services market and their joint activities inevitably raise questions of these alliances effectiveness assessing for the purpose of improving the competitiveness of their constituent structures in terms of synergies. In this case, in our opinion, the analysis of the effectiveness of integrated business forms should be based on a comparison of the two main final options. The first one involves an assessment of business activity of information - communication services operators outside of these associations at their full independence, and the second one involves the assessment of synergies from such association in the framework of relevant restrictions and obligations. Further these final options are compared on various indicators, but as the final integration effect should, in our opinion, serve the resulting difference between the values of the selected final indicator. Most often, to assess the cost-effectiveness indicator there used the indicator of net present value, as it is as a result of creation of new organizational business forms, resulting from integration processes, may serve as one of the possible assessments of a synergetic effect. It should always be remembered that these mentioned and traditional indicators of economic efficiency are not always adequate to the economic content of integration formations in the market of information - communication services focused on their own, sometimes narrow corporate and private-ownership, strategies of combining, livelihood and development.

It is natural that in the current conditions of market functioning and the specific of industry groups in the field of information - communication services there cannot be a unified system of indicators to measure the level of enterprise structures competitiveness. Each company within the industry peculiarities independently determines such a system, basing on their own ideas and purposes of assessment indicators. However, the formation of an assessment indicators system cannot be considered as a completely spontaneous process. In scientific and practical economic literature there is a certain set of requirements that assessment indicators of a competitiveness level must satisfy, among which the most important are the requirements of the systemacity, proportionality, complementarity, relative objectivity, possibility to express through absolute and relative terms, retrospectivness, possibility of comparison, accounting and analysis .

\section{Recommendations}

The obtained results allow to establish an effective system of management and the promotion of relations in the field of information - communication services in the region, to adapt the methodic of competitive strategy of market subject development in the regional market of information - communication services to the realities, to evaluate the relationship level of the socio-economic development of the region and the level of development of information - communication services regional market.

The results can be used as a basis for further scientific development of problems in the functioning of the regional market of information - communication services in the practice of all its subjects, as well as state regulatory agencies.

The results may be useful for students learning methods of marketing research in the service industries, as well as marketing specialists, operators who develop growth strategies for their companies.

\section{References}

Andreeva, L. \& E. Mirgorodskaya (2004). A look at the system competitiveness as a dominant of sustainable economic development. Economist, 1, 81-88.

Azoev, G.L., \& A.P. Chelenkov (2000). Competitive advantages of the company. News, 256.

Courbiev, I.U. \& S.V. Kiselev (2010). Peculiarities of competitive strategies development in the market of information and communication services. Herald of Kazan Technological University, 2, 135-140.

Danilin, A. (2004). E-government services and administrative regulations. INFRA-M, 336.

Efanov, A. V. (2006) What will happen to Russia in the market of fixed access? InformKuryerSvyaz, 5, 45-52.

Gelvanovsky, M.I. (2003). Globalization and National Competitiveness. Economic theory on the verge of XXI century. Jurist, 224.

Kotilko, V.V. \& I.I. Sanin. (2003). The development strategy of services. Saturn, 248.

Kotler, F. (1992). Principles of Marketing. Progress, 780.

Kulibanova, V.V. (2002). Marketing: service activities. Peter, 210.

Lifits, IM (2001) Theory and practice of assessing the competitiveness of goods and services. Moscow, 278.

Perminov, S.B. (2007) Information technologies as a factor of economic growth. Progress, 243. 
Rokotyan, A.U. (2006) The non-classical concept of telecommunications. InformKuryerSvyaz, 4, 12-19.

Schumpeter, J. (1982). The theory of economic development. Progress, 243.

Varakin, L.E. (2006). Information and economic law. Relationship of infocommunication infrastructure and economy. Moscow, 110. Zaynasheva, Z.G. \& G.V. Shkabarnya. (2004). New organizational forms of management and development of services. Ufa, 191. Zhiltsov, E.N. \& V.N. Kazakov (2007) The economy of social service industries. TEIS, 288. 